\section{Characterising the current provision of education and training courses relevant to the Replacement, Reduction and Refinement (Three Rs) of animals used for scientific purposes}

\author{
Adelaide Dura, Marcelle Holloway \\ European Commission, Joint Research \\ Centre, Ispra, Italy
}

\begin{abstract}
A recent study by the Joint Research Centre (JRC) of the European Commission showed that although much knowledge exists on the Three Rs (Replacement, Reduction and Refinement of animal procedures), there is a clear need for better education, communication and outreach to enhance knowledge sharing and promote their uptake. The JRC is now completing an extensive overview of the Three Rs education and training landscape by mapping currently available courses and resources worldwide. In addition, it has launched a project to investigate the feasibility of including the Three Rs in educational curricula under a European Parliament Pilot Project, which aims to promote alternatives to animal testing.
\end{abstract}

\section{Introduction}

In 2016 the European Commission's Joint Research Centre (JRC) carried out a study of available knowledge on the Three Rs (Replacement, Reduction and Refinement of animals used for scientific purposes) to understand how the supply of such knowledge could better meet demand. ${ }^{1}$ The study's findings show that, although much Three Rs knowledge exists, its sharing can be improved through better coordination, communication and outreach, and by more emphasis on targeted education and training initiatives.

As a follow-up, the current study was conducted $^{2}$ with the aim to characterise the education and training (E\&T) courses and resources relating to the Three Rs that are currently offered within and beyond the European Union and across three levels of learning: professional, university and high school. By characterising such courses and resources, an analysis of current trends as well as areas of strength and demand was carried out to inform further actions in accelerating the development and uptake of the Three Rs within an E\&T context.

\section{Materials and Methods}

The identification of E\&T courses and resources with an implicit or explicit mention of the Three Rs was carried out between June and September 2018. An online survey was disseminated publicly and to specific individuals and institutions to identify such E\&T programmes. ${ }^{3}$ The results were then integrated by a web-based search using PubMed and Google and employing a combination of keywords.

The resulting entries were further assessed according to predefined inclusion and exclusion criteria and characterised on the basis of several descriptors such as course title, language, format, education level, program accreditation and type of access (free or fee-based), Three Rs relevance.

\section{Results}

569 E\&T courses and resources with Three Rs relevance were identified in 52 countries worldwide, the majority located in Europe (72\%) and North America (16\%). In Europe more than 80 courses were delivered in the United Kingdom, whilst Germany, Switzerland and the Netherlands provided 41, 29 and 26 courses respectively (Figure). English was the most common teaching language $(80 \%)$ but several courses were also thought in more than one language, which usually includes English.

Several E\&T courses and resources combined both classroom and distance learning formats. Face-to-face education, in the form of lectures and hands-on-training, was identified as the most common format of delivery (64\%). On the other hand, distance learning through for example webinars or interactive online resources represented approximately one third $(30 \%)$ of the total courses and resources.

$70 \%$ of the identified E\&T courses and resources targeted university level (undergraduate, postgraduate and postdoctoral). Professionals were addressed by $26 \%$ of the courses and only $3 \%$ focused on high school-goers. Around $50 \%$ of the E\&T courses and resources were delivered exclusively in the form of fee-based access.

Approximately one third of the courses and resources focused on the Replacement principle and the second most addressed principle was Refinement (20\%), whilst a
Correspondence: Adelaide Dura, European Commission, Joint Research Centre, Ispra, Italy.

E-mail: adelaide.dura@ec.europa.eu

Key words: Three Rs; Dir2010/63/EU; alternatives; Education \& Training.

Conference presentation: this paper was presented at the Second Centro 3R Annual Meeting - 3Rs in Italian Universities, 2019, June 20-21, University of Genoa, Italy.

Received for publication: 28 October 2019. Accepted for publication: 6 November 2019

This work is licensed under a Creative Commons Attribution NonCommercial 4.0 License (CC BY-NC 4.0).

C Copyright: the Author(s), 2019

Licensee PAGEPress, Italy

Biomedical Science and Engineering 2019; 3(s2):88 doi:10.4081/bse.2019.88

few courses are offered on Reduction (8\%). $18 \%$ of the courses and resources addressed all the Three Rs principles.

\section{Conclusions}

This study represents a first attempt to identify and characterise the educational provision currently offered worldwide and relevant to the Three Rs. As highlighted in Holley et al., ${ }^{1}$ the education and training sector is one of the key pillars to accelerate the progress of the Three Rs.

The current study shows that there is a significant and rich number of Three Rs E\&T courses and resources available across six continents and accessible in different formats such as distance and/or classroom learning. However, certain methodologies and education levels dominates, as does the English language showing an uneven distribution around the globe. Massive open online courses and summer schools are underrepresented as teaching formats. In addition, high-school goers and professionals are the least targeted audience, while E\&T resources are mostly fee-based.

This study provides a firm basis for the formulation of future activities and actions in the field of Three Rs E\&T. The European Commission has already undertaken important next steps in the frame of the EU pilot project adopted by the European Parliament "Promoting alternatives to animal testing". Such initiatives intend to develop freely accessible resources and target particularly high-school goers and professionals. 
A feasibility study in support of the development of guidance for educators, educational institutes and relevant ministries is currently being carried out by the JRC and will be published in 2020. It will result in the actual guidance aiming at advising on effective ways of creating, adapting and implementing curricula and practices specific to the Three Rs. A set of free access teaching resources targeting the three levels of educations (high school, university, early career) will also be released. A special focus will be dedicated to highschools, for example involving teachers in co-creating learning scenarios and engaging with high-level stakeholders in the field of Three Rs and education specialists.

Six open access and interactive e-learning modules are being developed by Directorate-General Environment of the

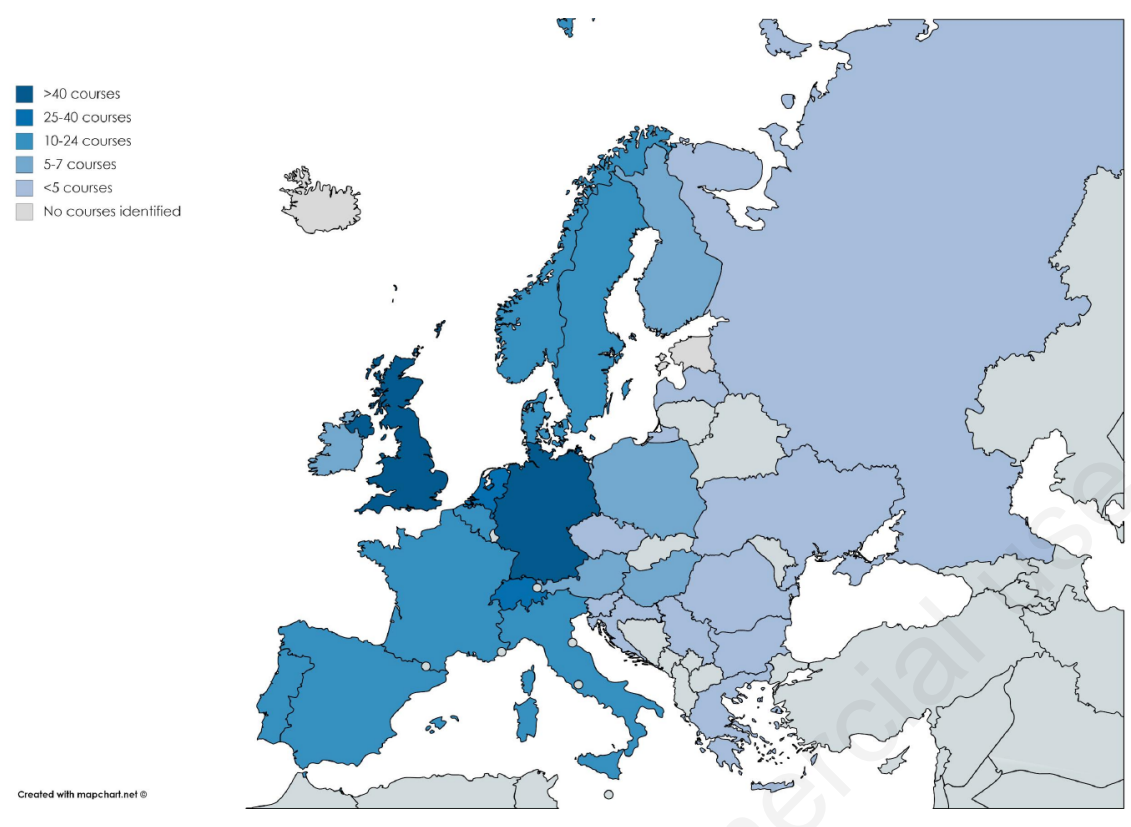

Figure 1. Distribution of the Three Rs E\&T courses and resources in Europe.
European Commission which is responsible for Directive 2010/63/EU on the protection of animals used for scientific purposes, and will be released in 2020 . Some modules will focus on how to search for non-animal alternatives and accelerate the timeline of new alternative methods from the development to regulatory acceptance, including also theory and practice of the OECD Guidance on good in vitro method practice (GIVIMP). Others will deal with the implementation of the Three Rs under the Directive 2010/63/EU and cover project design, project evaluation and application of the severity assessment framework.

\section{References}

1. Holley $\mathrm{T}$, Bowe $\mathrm{G}$, Campia I, et al. Accelerating progress in the Replacement, Reduction and Refinement of animal testing through better knowledge sharing. EUR 28234 EN. Luxembourg: Publications Office of the European Union; 2016.

2. Holloway M, ed. Review of Three Rs Education and Training Courses and Resources. EUR 29701 EN. European Commission; 2019.

3. Joint Research Centre. JRC launches survey on alternatives to animal testing. 4 June 2018. Available from: https://ec.europa.eu/jrc/en/news/jrclaunches-survey-alternatives-animaltesting_Accessed: 11 June 2019. 